\title{
Folic acid supplement use is the most significant predictor of folate concentrations in Canadian women of childbearing age
}

\author{
Cynthia K. Colapinto, Deborah L. O’Connor, Lise Dubois, and Mark S. Tremblay
}

\begin{abstract}
One-fifth of Canadian women of childbearing age (WCBA) have red blood cell (RBC) folate concentrations below those considered optimal for neural tube defect risk reduction $\left(\geq 906 \mathrm{nmol} \cdot \mathrm{L}^{-1}\right)$. Determinants of optimal concentrations have not been examined in a nationally representative sample of Canadian WCBA since food fortification with folic acid was implemented. This study explored correlates of optimal RBC folate concentrations and characteristics of folic acid supplement users in a sample of Canadian WCBA. RBC folate concentrations from the 2007-2009 Canadian Health Measures Survey were assessed in women aged 15 to 45 years $(n=1162)$. Sociodemographic, behavioural, and clinical determinants of RBC folate $\geq 906 \mathrm{nmol} \cdot \mathrm{L}^{-1}$ were examined using univariate and separate multiple logistic regression models that controlled for age and household income. $t$ tests were used to study differences between folic acid supplement users and nonusers. WCBA not taking folic acid supplements were less likely to achieve a RBC folate concentration $\geq 906 \mathrm{nmol} \cdot \mathrm{L}^{-1}$ compared with folic acid supplement users (odds ratio, 0.47 ; $95 \%$ confidence interval, 0.24, 0.92). Twenty-five percent of WCBA reported folic acid supplement use, and there was a higher percentage of folic acid supplement users in the highest income group. Folic acid supplement users were also more frequent consumers of supplemental vitamin $\mathrm{B}_{12}$ and of fruit and vegetables ( $>3$ times per day). Folic acid supplement use was the most significant predictor of WCBA achieving optimal RBC folate concentrations. These results indicate a need for targeted strategies to improve compliance with folic acid supplement recommendations among WCBA.
\end{abstract}

Key words: red blood cell (RBC) folate, folic acid, supplementation, Canadian Health Measures Survey (CHMS).

Résumé : Un cinquième des Canadiennes en âge de procréer (WCBA) présente une concentration érythrocytaire (RBC) de folate sous le seuil considéré optimal pour diminuer le risque d'anomalie du tube neural $\left(\geq 906 \mathrm{nmol} \cdot \mathrm{L}^{-1}\right)$. Il n'y a pas eu d'études sur les déterminants de la concentration optimale dans un échantillon représentatif des WBCA sur le plan national depuis la mise en œuvre de l'enrichissement des produits alimentaires en acide folique. Cette étude analyse les corrélats de la concentration optimale d'acide folique dans les RBC et les caractéristiques des consommatrices de supplément d'acide folique dans un échantillon canadien de WBCA. On évalue la concentration érythrocytaire de folate dans un échantillon de l'Enquête canadienne sur les mesures de la santé 2007-2009 (CHMS) comprenant des femmes âgées de 15 à 45 ans $(n=$ 1162). On cherche les déterminants sociodémographiques, comportementaux et cliniques d'une concentration érythrocytaire de folate $\geq 906 \mathrm{nmol} \cdot \mathrm{L}^{-1}$ au moyen de modèles de régression univariée et de régression logistique multiple prenant en compte l'âge et le revenu du ménage. On utilise des tests t pour analyser les différences entre les consommatrices de supplément en acide folique et celles qui n'en consomment pas. Les WCBA qui ne prennent pas de supplément en acide folique ont vraisemblablement une probabilité moindre de présenter une concentration érythrocytaire de folate $\geq 906 \mathrm{nmol} \cdot \mathrm{L}^{-1}$ que les consommatrices de supplément (OR 0,47, I C : 0,24-0,92). Vingt-cinq pour cent des WBCA disent consommer des suppléments d'acide folique et chez ces consommatrices, on enregistre un plus haut pourcentage de femmes dans des ménages à plus haut revenu. Les consommatrices de supplément d'acide folique prennent aussi plus souvent des suppléments de vitamine $\mathrm{B}_{12}$ de même que des fruits et des légumes soit plus de 3 fois par jour. La prise de supplément d'acide folique est le prédicteur le plus significatif chez les WCBA pour l'atteinte de la concentration optimale de folate dans les érythrocytes. Ces observations soulignent la nécessité de stratégies de concertation pour améliorer la conformité à l'égard des recommandations en matière de supplémentation en acide folique chez les WCBA.

Received 18 October 2011. Accepted 2 December 2011. Published at www.nrcresearchpress.com/apnm on 27 March 2012.

C.K. Colapinto. Healthy Active Living and Obesity Research Group, Children's Hospital of Eastern Ontario Research Institute (CHEO-RI), 401 Smyth Road, Room 242, Ottawa, ON K1H 8L1, Canada; Institute of Population Health, University of Ottawa, Ottawa, ON K1N 6N5, Canada.

D.L. O'Connor. Department of Clinical Dietetics; Physiology and Experimental Medicine Program, The Hospital for Sick Children, Room 8511C, 555 University Avenue, Toronto, ON M5G 1X8, Canada; Department of Nutritional Sciences, University of Toronto, Toronto, ON M5S 3E2, Canada.

L. Dubois. Department of Epidemiology and Community Medicine, Faculty of Medicine, Institute of Population Health, University of Ottawa, 1 Stewart Street, Office 303, Ottawa, ON K1N 6N5, Canada.

M.S. Tremblay. Healthy Active Living and Obesity Research Group, Children's Hospital of Eastern Ontario Research Institute (CHEO-RI), 401 Smyth Road, Room 211, Ottawa, ON K1H 8L1, Canada; Department of Pediatrics, University of Ottawa, Ottawa, ON K1H 8L1, Canada.

Corresponding author: Cynthia K. Colapinto (e-mail: colapinto@uottawa.ca). 
Mots-clés : folate érythrocytaire, acide folique, supplémentation, Enquête canadienne sur les mesures de la santé.

[Traduit par la Rédaction]

\section{Introduction}

The role of folic acid intake in the prevention of neural tube defects (NTDs) is well established (Refsum 2001). While folate occurs naturally in food, folic acid is the most common synthetic form of folate found in fortified foods and supplements. In Canada, women of childbearing age (WCBA) are encouraged to eat folate-rich foods and to take a multivitamin supplement containing folic acid $\left(0.4 \mathrm{mg} \cdot \mathrm{day}^{-1}\right)$ to further reduce the risk of folate-dependent NTDs (Health Canada 2010a). Higher-dose supplements (4-5 mg.day ${ }^{-1}$ ) are recommended for women at increased risk of a NTD birth (Health Canada 2010b). Given that up to $50 \%$ of pregnancies are unplanned and that many WCBA report irregular or no consumption of folic acid prior to pregnancy, in 1998, Canadian policymakers approved the fortification of white wheat and other select grains with folic acid, in addition to supplementation recommendations (Berry et al. 2010).

NTD births in Canada have been reduced by $46 \%$ since the implementation of fortification with folic acid, demonstrating the success of this intervention (De Wals et al. 2008). In addition, folate deficiency (red blood cell (RBC) folate $\left.<305 \mathrm{nmol} \cdot \mathrm{L}^{-1}\right)$ is virtually nonexistent in the general Canadian population (Colapinto et al. 2011). Despite this absence of deficiency, approximately $22 \%$ of Canadian WCBA are still not achieving a folate concentration considered optimal for NTD risk reduction $\left(\geq 906 \mathrm{nmol} \cdot \mathrm{L}^{-1}\right)$ (Daly et al. 1995; Colapinto et al. 2011). Because this segment of the population is the target of fortification and supplementation policies, clarifying the factors associated with achieving optimal folate status is essential to refining interventions.

Although certain factors (e.g., adolescence, low socioeconomic status, low consumption of folate-rich foods, poor compliance with folic acid supplements, smoking, and maternal obesity) are known to be related to NTDs, the association of these factors with folate concentrations $\geq 906 \mathrm{nmol} \cdot \mathrm{L}^{-1}$ has not been investigated on a nationally representative Canadian sample since the implementation of food fortification with folic acid (Tam et al. 2009). This study addresses this knowledge gap by exploring correlates of RBC folate concentrations considered optimal for NTD risk reduction and of folic acid supplement use in Canadian WCBA, using the Canadian Health Measures Survey (CHMS).

\section{Materials and methods}

Data from the 2007-2009 CHMS, conducted by Statistics Canada in partnership with Health Canada and the Public Health Agency of Canada, were used for these analyses. The survey methodology is described briefly here and in detail elsewhere (Bryan et al. 2007).

\section{CHMS sampling}

The CHMS used a complex, multistage, cluster-sampling protocol to achieve a nationally representative cross-sectional sample. The final sample comprised 5604 Canadians aged 6-
79 years, balanced by sex, in each of the following age groups: 6-11, 12-19, 20-39, 40-59, and 60-79 years. This is representative of approximately $96.3 \%$ of the Canadian population.

\section{Survey methods}

Data collection occurred between March 2007 and February 2009. An interviewer administered a detailed in-home health questionnaire, which included data on sociodemographic characteristics. One day to 6 weeks later, blood samples were taken by a phlebotomist in a mobile examination centre to measure a variety of analytes, including RBC folate (Bryan et al. 2007). Implied consent occurred in the household, and a comprehensive consent process was employed in the clinic. Ethics approval for the CHMS was obtained from the Health Canada Research Ethics Board and, for this secondary data analysis, from the Children's Hospital of Eastern Ontario and University of Ottawa Research Ethics Boards.

\section{Blood sampling}

Blood was drawn from 5373 CHMS participants, with 1162 WCBA (15-45 years old, including 29 reporting pregnancy) providing a sample for RBC folate measurement, weighted to represent approximately 6676460 Canadians. Participants in this subgroup who refused to participate in the blood draw or who did not have a usable sample were excluded $(n=45)$.

\section{RBC folate concentration}

RBC folate allows for an estimate of tissue folate stores (McNulty et al. 2011). Venipuncture samples were collected in EDTA-treated vacutainers, then immediately processed on site. After hematocrit measurement, aliquots of whole blood were frozen, stored at $-20{ }^{\circ} \mathrm{C}$, and shipped weekly to the Health Canada nutrition laboratory on dry ice (Bryan et al. 2007). Samples were thawed, diluted (1-in-26) with $0.5 \%$ ascorbic acid solution, allowed to incubate for $180 \mathrm{~min}$ at room temperature, and then analyzed for RBC folate, using the Immulite 2000 immunoassay (Siemens Canada Ltd., Mississauga, Ont., Canada) (Siemans Canada 2009). RBC folate concentration was calculated from the measured whole-blood folate concentration, adjusted for RBC volume, without correction for plasma folate concentration. Accuracy and reproducibility of these procedures was assessed using the manufacturers' serum controls (Con6: Tri-level multiconstituent control) and whole-blood controls (BioRad Lyphochek Tri-level; BioRad Laboratories, Hercules, Calif., USA). Serum controls had an interassay coefficient of variation of $<5 \%$, and all analyzed controls (serum, whole blood) were within $10 \%$ of target values.

The folate concentration considered optimal for NTD risk reduction among WCBA was set at $\geq 906 \mathrm{nmol} \cdot \mathrm{L}^{-1}$, which was derived from a large Irish case-control study of antenatal 
women from 1986 to 1990 that demonstrated a continuous, inverse dose-response relationship between $\mathrm{RBC}$ folate concentration (up to $1292 \mathrm{nmol} \cdot \mathrm{L}^{-1}$ ) and NTD risk (Daly et al. 1995). The cut-off of $906 \mathrm{nmol} \cdot \mathrm{L}^{-1}$ represents the lower boundary of the uppermost RBC folate concentration group in this study population, as well as the category with the lowest risk of a NTD birth. This cut-off has been widely adopted by experts in the field (Daly et al. 1995; Institute of Medicine 1998).

\section{Correlates of optimal RBC folate concentration for NTD risk reduction}

\section{Sociodemographic factors}

A variable for WCBA (aged 15 to 45 years) was derived. Socioeconomic status was examined by per-person household-income equivalents (which grouped respondents into quartiles after adjustment for family size and composition) and the highest level of household education (less than postsecondary graduation and postsecondary graduation) (Statistics Canada 2008). Participants were categorized dichotomously as born or not born in Canada.

\section{Behavioural factors}

\section{Supplement intake}

Drug identification and natural health product numbers were collected from containers shared by participants during the household visit. This information was verified during the clinic visit; changes in drug and supplement usage were also collected at this time (Statistics Canada 2011a). Supplemental folic acid use - whether consumed alone or as a multivitamin - in the 30 days prior to the clinic visit was determined by matching drug identification and natural health product numbers to product information extracted from the Health Canada Drug Product and Licensed Natural Health Product databases (Statistics Canada 2011a; Health Canada 2011a, 2011b). This approach was also used to quantify vitamin $\mathrm{B}_{12}$ supplement use - again, whether consumed alone or as a multivitamin.

\section{Intake of folate-rich foods}

A brief, nonquantitative food frequency questionnaire was used to examine the usual frequency of consumption from the grains and fruit and vegetables categories to assess dietary habits for food sources of folate (Statistics Canada 2011a). Combined, these food groups have been shown to represent $62 \%$ to $78 \%$ of dietary folate intake in the Canadian diet (Sherwood et al. 2006; Shuaibi et al. 2008; Statistics Canada 2011a). The derived variable for fruit and vegetables included usual intake of fruit, tomatoes, lettuce, dark greens, and other vegetables - not including juices or potatoes. Usual intake of cereal, white bread, brown bread, and pasta were combined to formulate the derived variable for grains.

\section{Smoking}

Self-reported smoking status and history were used to categorize participants as current, former, or never smokers.

\section{Physical activity}

A physical activity index of active, moderately active, or inactive was derived on the basis of average daily energy ex- penditure values during self-reported leisure time activities in the 3 months prior to the household visit (Statistics Canada 2011b).

\section{Clinical factors}

Derived variable for clinical risk factor

A derived variable was created to combine self-reported diabetes mellitus, use of folic acid antagonist medication, and overweight/obese. Drug identification numbers were matched to data extracts from the Drug Product Database to identify folic acid antagonist medication consumption in the 30 days prior to the clinic visit (Stabler 2010; Statistics Canada 2011a). Measured height and weight were used to calculate body mass index (BMI; $\mathrm{kg} \cdot \mathrm{m}^{-2}$ ), which was then used to classify participants as neither overweight nor obese, or overweight/obese. The BMI status of adults, excluding pregnant women, was classified using Health Canada's guidelines (BMI of 25 to $29.9 \mathrm{~kg} \cdot \mathrm{m}^{-2}$ indicates overweight; BMI of $>30 \mathrm{~kg} \cdot \mathrm{m}^{-2}$ indicates obesity) (Health Canada 2003). Participants aged 15 to 17 years were classified as being normal weight, overweight, or obese, based on definitions proposed by the International Obesity Task Force (Cole et al. 2000). BMI was also examined as a separate predictor.

\section{Vitamin $B_{12}$ concentrations}

Serum vitamin $B_{12}$ was assessed using the Immulite 2000 immunoassay, a solid-phase, competitive chemiluminescent enzyme immunoassay involving an automated alkaline denaturation procedure. The cut-off for marginal vitamin $\mathrm{B}_{12}$ status was determined to be $\leq 221 \mathrm{pmol} \cdot \mathrm{L}^{-1}$ (Siemans Canada 2006; Allen 2009).

\section{Statistical analysis}

Descriptive statistics (frequencies, percentiles) were used to characterize the population. Missing values for predictor variables were removed for individual analysis. Univariate logistic regression analysis was used to examine each covariate as a correlate of folate concentrations $\geq 906 \mathrm{nmol} \cdot \mathrm{L}^{-1}$; it was followed by a separate logistic regression analysis that controlled for age and income. $t$ tests were used to study the differences between folic acid supplement users and nonusers for each correlate. All estimates were based on data weighted to represent the Canadian population. Variance estimation (95\% confidence intervals) and significance testing were based on the bootstrap technique to account for the complex sampling design (Rust and Rao 1996). Analyses were conducted with SAS 9.1.3 (SAS Institute Inc., Cary, N.C., USA) and SUDAAN v.10.0 (RTI International, Research Triangle Park, N.C., USA), using DDF $=11$ in the SUDAAN procedure statements. Given the 11 degrees of freedom available for variance estimation, Satterthwaite-adjusted statistics were used to test the significance $(p<0.05)$ of each regression model's coefficients, rather than testing the significance of individual parameters (Bushnik et al. 2010).

\section{Results}

\section{Prevalence of $\mathrm{RBC}$ folate concentrations $\geq 906 \mathrm{nmol} \cdot \mathrm{L}^{-1}$}

The greatest proportion of $\mathrm{RBC}$ folate concentrations $\geq 906 \mathrm{nmol} \cdot \mathrm{L}^{-1}$ occurred in the highest income quartile (Table 1). The 2 older age groups (20-45 years of age) had a 


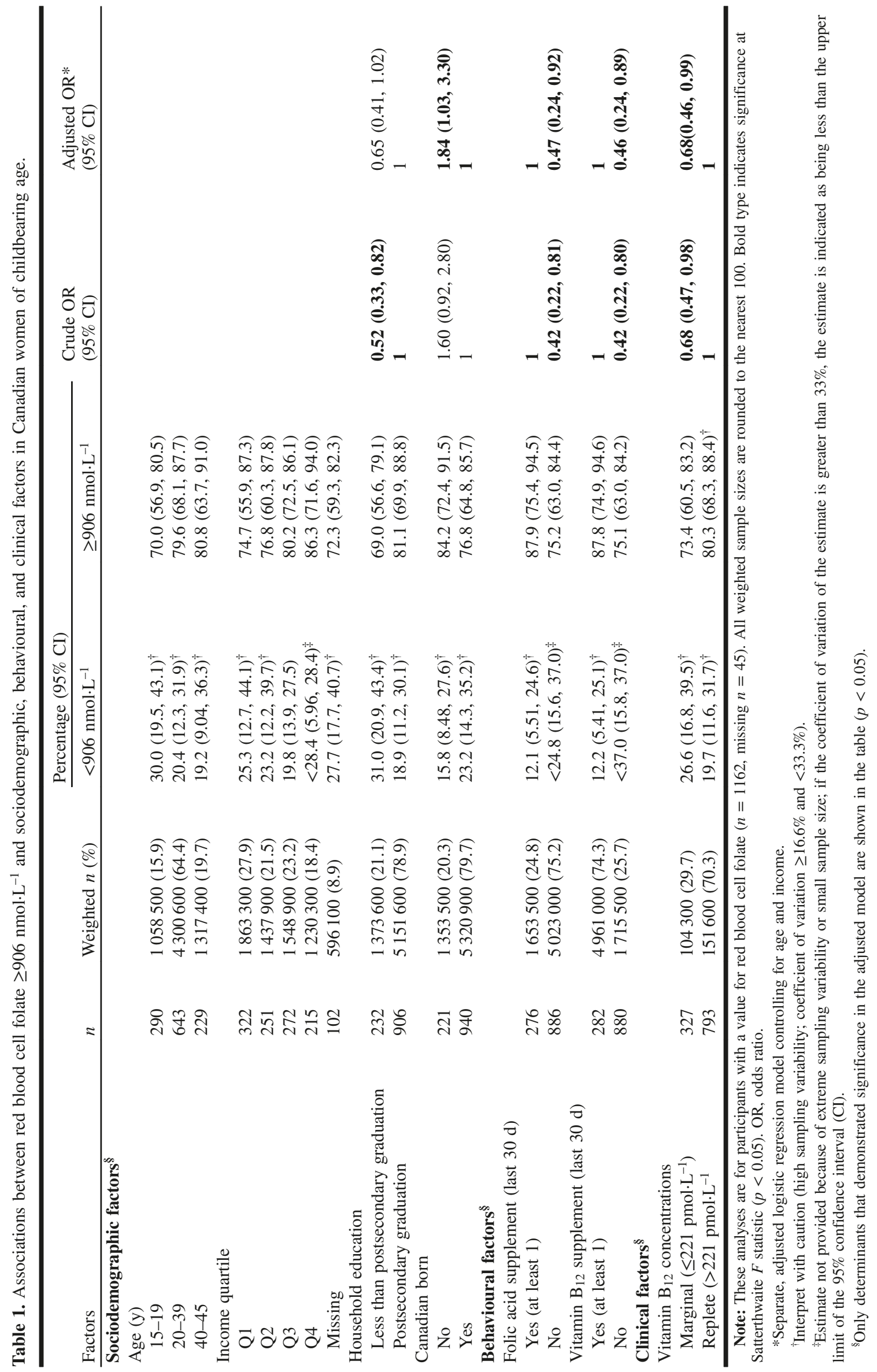


higher prevalence of $\mathrm{RBC}$ folate $\geq 906 \mathrm{nmol} \cdot \mathrm{L}^{-1}$ than the youngest age group. A total of $24.8 \%$ of the study population reported taking a folic acid supplement in the 30 days prior to the clinic visit. Folic acid supplement users had a greater prevalence of $\mathrm{RBC}$ folate concentration $\geq 906 \mathrm{nmol} \cdot \mathrm{L}^{-1}$ (87.9\%) than nonusers $(75.2 \%)$.

\section{Correlates of $\mathrm{RBC}$ folate concentrations $\geq 906 \mathrm{nmol} \cdot \mathrm{L}^{-1}$}

Participants who did not report folic acid supplement consumption were significantly less likely to have a folate concentration $\geq 906 \mathrm{nmol} \cdot \mathrm{L}^{-1}$ (Table 1), after controlling for age and income. For example, WCBA who did not report taking a folic acid supplement were less likely to have folate concentrations $\geq 906 \mathrm{nmol} \cdot \mathrm{L}^{-1}$ than folic acid supplement users (odds ratio (OR) 0.47 ; 95\% CI 0.24, 0.92; Satterthwaite $F$ statistic < 0.05). Participants not born in Canada were more likely than Canadian-born participants to have folate concentrations $\geq 906 \mathrm{nmol} \cdot \mathrm{L}^{-1}$ (OR 1.84; $95 \%$ CI $1.03,3.30$ ). Participants who consumed supplements containing vitamin $\mathrm{B}_{12}$ were also more likely than nonconsumers to have a RBC folate concentration $\geq 906 \mathrm{nmol} \cdot \mathrm{L}^{-1}$ (OR 0.46 ; $95 \%$ CI 0.24 , 0.89). Participants with marginal vitamin $B_{12}$ status were significantly less likely to have optimal folate concentrations than those who were vitamin $\mathrm{B}_{12}$ replete (OR $0.68 ; 95 \%$ CI $0.46,0.99)$.

\section{Differences between folic acid supplement users and nonusers}

Twenty-five percent of Canadian WCBA reported consuming a folic acid supplement. A higher prevalence of folic acid supplement users than nonusers were in the highest income quartile $(28.8 \%$ (95\% CI 22.5, 36.1) and $15.0 \%$ (95\% CI 12.7, 17.7), respectively) (Table 2). Conversely, nonusers were more prevalent than users in the lowest income quartile (30.9\% (95\% CI 23.9, 38.8) and 18.9 (95\% CI 10.3, 32.1), respectively). Folic acid supplement users were more prevalent in association with vitamin $B_{12}$ supplement use. A higher percentage of folic acid supplement use was evident among participants who consumed fruit and vegetables 3 or more times per day, and lower in participants who consumed fruit and vegetables less than once per day.

The cumulative percent distributions for supplement users and nonusers are shown in Fig. 1. The median RBC folate concentration for folic acid supplement users was significantly higher than that for nonusers, although both groups had a median $\mathrm{RBC}$ folate $\geq 906 \mathrm{nmol} \cdot \mathrm{L}^{-1}\left(1470 \mathrm{nmol} \cdot \mathrm{L}^{-1}\right.$ and $1141 \mathrm{nmol} \cdot \mathrm{L}^{-1}$, respectively) (Fig. 1).

\section{Discussion}

This study provides new information on the correlates of RBC folate concentrations considered optimal for NTD reduction in Canadian WCBA since fortification of the food supply with folic acid began. The most significant correlate of optimal RBC folate concentration for this subgroup was folic acid supplement intake, which in turn was significantly related to income, with a greater percentage of folic acid supplement users in the highest income group.

Studies of subgroups of WCBA have demonstrated comparable results, showing folic acid supplement intake as a strong, modifiable factor associated with RBC folate concen- trations $\geq 906 \mathrm{nmol} \cdot \mathrm{L}^{-1}$. For example, 40 healthy women, aged 18-45 years, from Toronto, who did not use supplements, were randomly assigned to consume supplements of $5.0 \mathrm{mg}$ or $1.1 \mathrm{mg}$ for 30 weeks. This resulted in an increase in mean $\mathrm{RBC}$ folate concentrations, from $1121 \pm$ $410 \mathrm{nmol} \cdot \mathrm{L}^{-1}$ and $1035 \pm 273 \mathrm{nmol} \cdot \mathrm{L}^{-1}$ to $2339 \pm$ $782 \mathrm{nmol} \cdot \mathrm{L}^{-1}$ and $1625 \pm 339 \mathrm{nmol} \cdot \mathrm{L}^{-1}$, respectively (Nguyen et al. 2009). In the United States, postfortification data showed that in a prospective sample of primarily white women, aged 22 to 25 years, supplement use was a strong predictor of RBC folate concentration, and folic acid supplement users had a higher mean RBC folate $\left(983 \pm 65 \mathrm{nmol} \cdot \mathrm{L}^{-1}\right)$ than nonusers (Brown et al. 1997). Another sample of nonsupplementing WCBA from the National Health and Nutrition Examination Survey (NHANES) was examined before and after the fortification of the food supply with folic acid, revealing that $90 \%$ of the sample participants were not achieving levels associated with NTD risk reduction (Dietrich et al. 2005). Further, a study of a sample of healthy pregnant women from Northern Ireland revealed that the proportion of women with RBC folate concentrations $<906 \mathrm{nmol} \cdot \mathrm{L}^{-1}$ increased if they started taking folic acid later in the prenatal period, from $27 \%$ at preconception, to $38 \%$ at $0-6$ gestational weeks, to $53 \%$ at $\geq 6$ gestational weeks (McNulty et al. 2011).

A recent study of the CHMS data showed that one-fifth of Canadian WCBA are not achieving optimal concentrations of $\mathrm{RBC}$ folate, although this subgroup is not folate deficient (RBC folate $<305 \mathrm{nmol} \cdot \mathrm{L}^{-1}$ ) (Colapinto et al. 2011); median folate concentrations were greater than the cut-off of $906 \mathrm{nmol} \cdot \mathrm{L}^{-1}$ for both supplement users and nonusers. Folic acid supplement use in our study population was comparable to another nationally representative study of Canadians (the 2004 Canadian Community Health Survey), which demonstrated consumption in $15 \%, 23 \%$, and $29 \%$ of women aged 14-18, 19-30, and 31-50 years, respectively (Shakur et al. 2010). The 2006 Maternity Experiences Survey, which examined women giving birth in Canada, found that $58 \%$ of these women reported taking folic acid at some point during the 3 months before conception (Chalmers et al. 2008). Further, in the United States, similar population-level data (20032006 NHANES) demonstrated that $25 \%$ of WCBA consumed a folic acid supplement (Tinker et al. 2010). The correlation between lower income and decreased prevalence of folic acid supplement use was also reflected in a systematic review of international research (1989 to 2006) on folic acid supplement intake, as well as in a study of the 2004 Canadian Community Health Survey data (Stockley and Lund 2008; Vatanparast et al. 2010). Considering the possible income disparity related to folate concentration and supplement intake established in our study, and the similar inequality that has been identified for NTD risk, low-income WCBA may be an important target population for folic acid supplement interventions. Interestingly, participants who are not Canadian born were more likely to have folate concentrations $\geq 906 \mathrm{nmol} \cdot \mathrm{L}^{-1}$, but no significant relationship was found between birth place and folic acid supplement intake. Factors such as specific dietary habits, country of origin, and length of time since immigration to Canada - the study of which are beyond the scope of this analysis - may provide insight into this finding. 
Table 2. Folic acid supplement use in Canadian women of childbearing age.

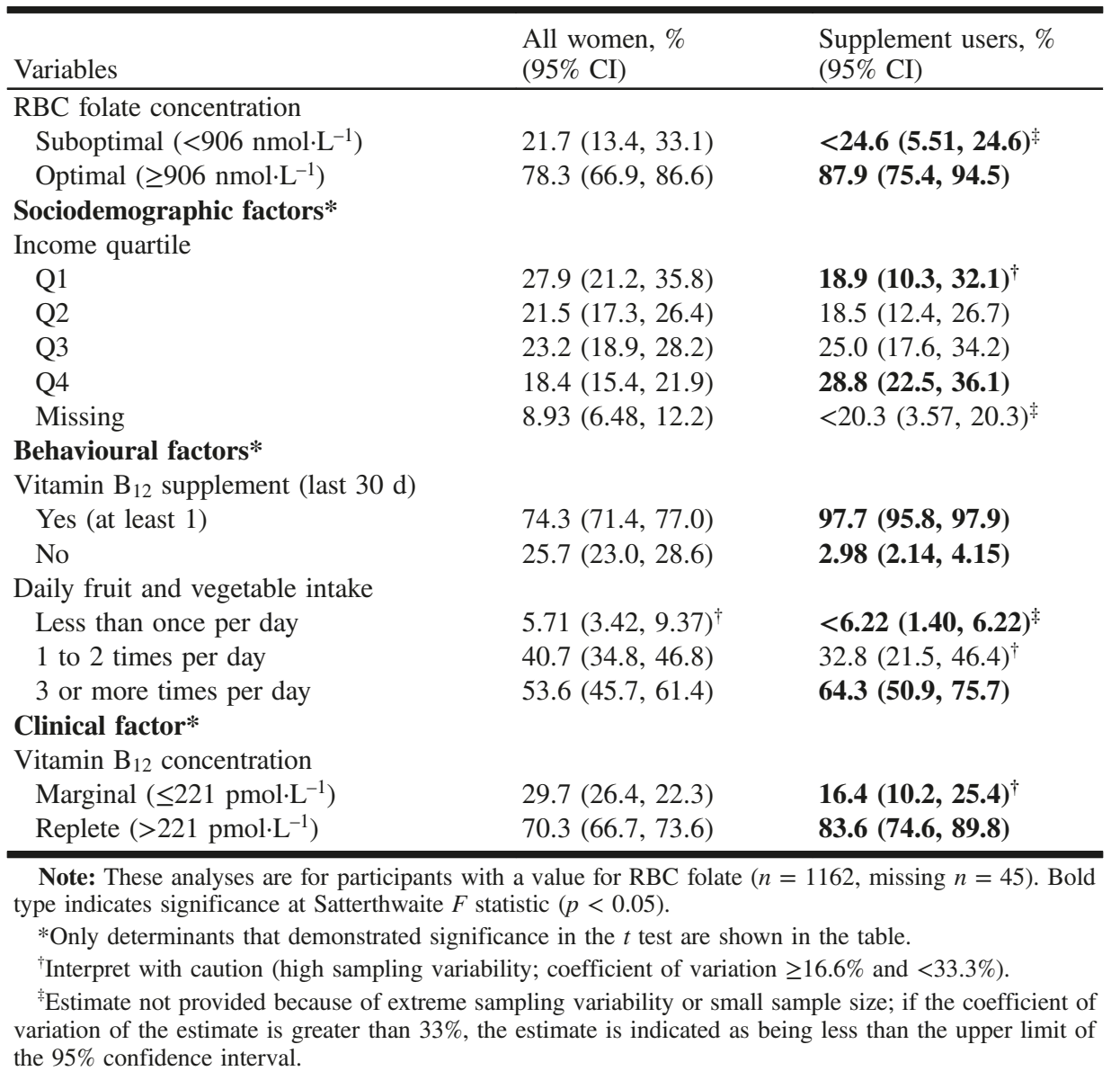

Fig. 1. Cumulative percentile distributions of red blood cell folate concentrations by folic-acid supplement use from the 2007-2009 Canadian Health Measures Survey. Folate concentrations considered optimal for maximal neural tube defect risk reduction $\left(906 \mathrm{nmol} \cdot \mathrm{L}^{-1}\right)$ is indicated by the vertical line. The median folate concentration for each group is indicated by the dashed horizontal line. *, Significant difference in medians.

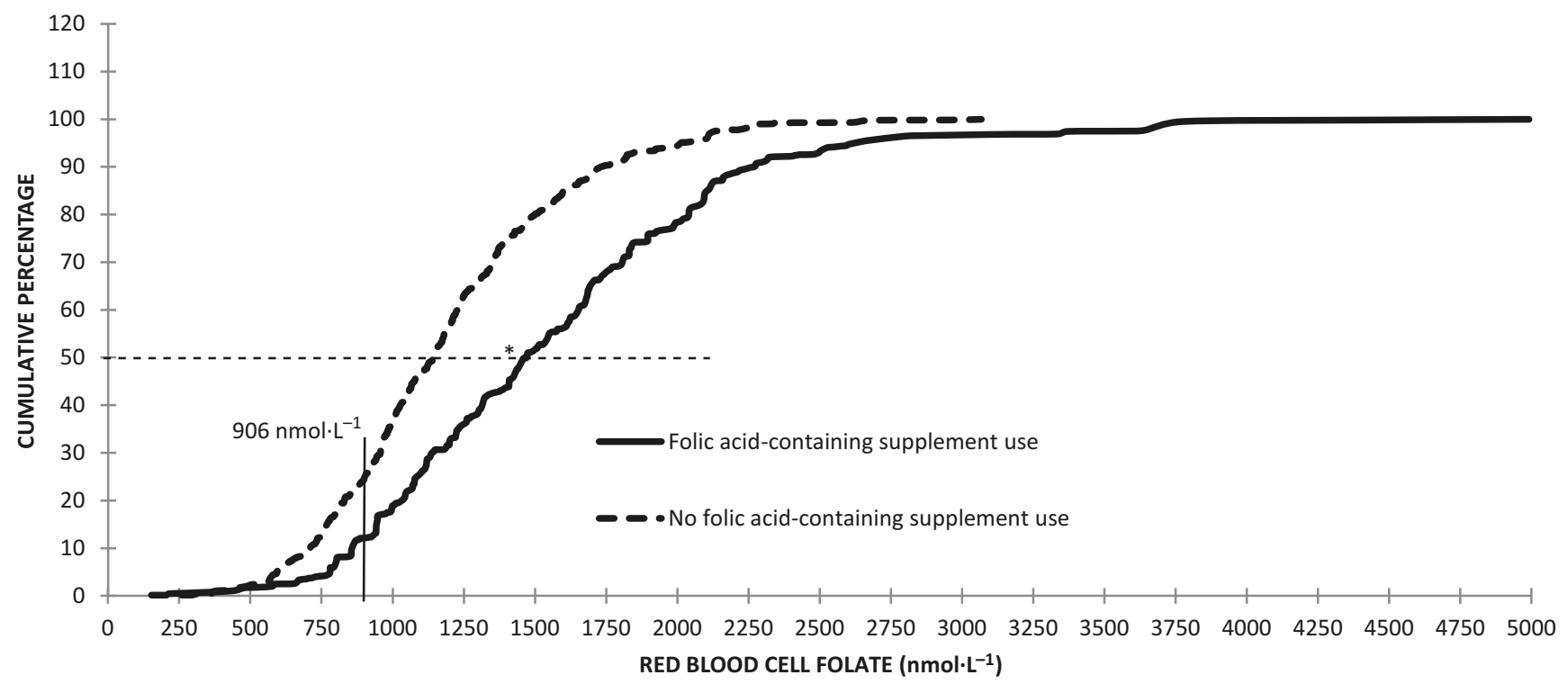

Conflicting findings regarding the health impact of consuming folic acid may lead women to become disenchanted with periconceptional folic acid supplement use, regardless of the undisputed benefit of NTD risk reduction and the important link between optimal folate concentration and lower risk of congenital heart disease and oral clefts. Fuelling this 
controversy is a recent study suggesting that supplement use does not offer an additional benefit for NTD risk reduction when taken with grains that are fortified with folic acid (Ahrens et al. 2011). Further, an association between folic acid supplement use and adverse health outcomes - including an increased risk of asthma, obesity, insulin resistance, and breast cancer in offspring — has been hypothesized, and there is speculation that there is a link between the high intake of folic acid and an increased risk of cancer in those with pre-existing neoplasms, and the potential for vitamin $\mathrm{B}_{12}$ masking (Mason et al. 2007; Cole et al. 2007; Yajnik et al. 2008; Allen 2009; Hirsch et al. 2009; Ly et al. 2011). It is notable that in our study, the participants with marginal vitamin $B_{12}$ status were less likely to have optimal RBC folate concentrations. This may be due to a lower intake of supplements containing vitamin $\mathrm{B}_{12}$, which in our sample often appeared to be taken in combination with folic-acid-containing supplements, a behaviour that is supported by Canadian guidelines (Health Canada 2010b). This study reinforces the importance of taking folic acid supplements to achieve optimal concentrations.

This research used a nationally representative study, which included a large sample size, directly measured biomarkers, and access to drug identification numbers and natural health product numbers. The cross-sectional nature of the CHMS does not allow for causal inferences, and the number of independent variables included in the regression model was limited by the 11 degrees of freedom. Future cycles of the CHMS would benefit from the inclusion of more detailed nutrition information to complement RBC folate concentration data, so that the impact of folate-related policies can be more thoroughly examined over time. WCBA incapable of becoming pregnant, for reasons of physiology or medication use, were not examined separately in this study.

It has been established that interlaboratory differences in values for $\mathrm{RBC}$ folate exist, although $\mathrm{RBC}$ folate is defined by the Institute of Medicine as the primary biochemical index to formulate the dietary reference intakes (Institute of Medicine 1998; Pfeiffer et al. 2010). As a result, study-to-study comparisons need to be performed with caution. It is acknowledged that the cut-off used in our study is assay dependent; however, it is standard practice to use the same cutoff values, regardless of RBC folate methods. For example, the US Centres for Disease Control and Prevention reported that at least 1 competitive binding assay resulted in RBC folate concentrations approximately 30\% lower than either microbiological or liquid chromatography-tandem mass spectrometry (Fazili et al. 2008). Notably, the RBC folate cut-off of $906 \mathrm{nmol} \cdot \mathrm{L}^{-1}$ used in this study was initially established by Daly et al. (1995), using a microbiological assay, except in our study, no correction was made for serum folate concentration. We employed strict quality-control procedures to ensure both the accuracy and precision of the RBC folate measurements to minimize this limitation.

The RBC folate cut-off of $906 \mathrm{nmol} \cdot \mathrm{L}^{-1}$ represents the upper limit of the continuous, inverse dose-response relationship between RBC folate concentration and folate-dependent NTDs theorized by Daly et al. (1995), and should not be considered an absolute determinant of folate-dependent NTD risk. Future research investigating the incidence of folatedependent NTDs, optimal RBC folate concentration, and folic acid supplement use is needed to provide insight into this relationship.

In conclusion, folic acid supplement use was the most significant predictor of WCBA achieving optimal RBC folate concentrations for maximal NTD risk reduction. The importance of folic acid supplementation for WCBA must be distinguished from the needs of the general population. Future research is needed to investigate the dose and duration of intake that is most favourable for achieving optimal concentrations in different populations. These data indicate a need for targeted strategies to improve compliance with folic acid supplement recommendations to assist WCBA in achieving desired folate concentrations.

\section{Acknowledgements}

The authors thank the Health Analysis Division at Statistics Canada, in particular Tracey Bushnik and Michelle Rotermann for their support during the analysis stage of this research, and the Physical Health Measures Division at Statistics Canada for preparing and granting special access to data. The authors also thank Trevor Stewart for his review and feedback on the manuscript. This research was supported by a CIHR Health Professionals Fellowship in the area of public health to Cynthia Colapinto (funding reference no. 180375) and a CIHR Operating Grant (funding reference no. 218776). Authors statement of contributions: All of the authors contributed to the conception and design of the study. Cynthia Colapinto conducted the analysis, and all authors assisted in the interpretation of the results. Cynthia Colapinto drafted the manuscript, and all authors critically reviewed the manuscript for important intellectual content and approved the final version submitted for publication.

\section{References}

Ahrens, K., Yazdy, M.M., Mitchell, A.A., and Werler, M.M. 2011. Folic acid intake and spina bifida in the era of dietary folic acid fortification. Epidemiology, 22(5): 731-737. doi:10.1097/EDE. Ob013e3182227887. PMID:21659881.

Allen, L. 2009. How common is vitamin B-12 deficiency? Am. J. Clin. Nutr. 89(2 Supp): 693S-696S. doi:10.3945/ajen.2008. 26947A. PMID:19116323.

Berry, R.J., Mulinare, J., and Hamner, H. 2010. Folic acid fortification: Neural tube defect risk reduction - A global perspective. In Folate in health and disease. 2nd ed. Edited by L.B. Bailey. CRC Press; Taylor \& Francis Group. Boca Raton, Fla., USA. pp. 179-204.

Brown, J.E., Jacobs, D.R., Jr, Hartman, T.J., Barosso, G.M., Stang, J.S., Gross, M.D., and Zeuske, M.A. 1997. Predictors of red cell folate level in women attempting pregnancy. JAMA, 277(7): 548552. doi:10.1001/jama.1997.03540310046033. PMID:9032161.

Bryan, S., St-Denis, M., and Wojtas, D. 2007. Canadian Health Measures Survey: clinic operations and logistics. Health Rep. 18(Suppl.): 53-70. PMID:18210870.

Bushnik, T., Haines, D., Levallois, P., Levesque, J., Van Oostdam, J., and Viau, C. 2010. Lead and bisphenol A concentrations in the Canadian population. Health Rep. 21(3): 7-18. PMID:20973429.

Chalmers, B., Dzakpasu, S., Heaman, M., and Kaczorowski, J. 2008. The Canadian Maternity Experiences Survey: An overview of findings. J. Obstet. Gynaecol. Can. 30(3): 217-228. PMID: 18364099.

Colapinto, C.K., O’Connor, D.L., and Tremblay, M.S. 2011. Folate 
status of the population in the Canadian Health Measures Survey. CMAJ, 183(2): E100-E106. doi:10.1503/cmaj.100568. PMID: 21149516.

Cole, B.F., Baron, J.A., Sandler, R.S., Haile, R.W., Ahnen, D.J., Bresalier, R.S., et al.Polyp Prevention Study Group. 2007. Folic acid for the prevention of colorectal adenomas: A randomized clinical trial. JAMA, 297(21): 2351-2359. doi:10.1001/jama.297. 21.2351. PMID:17551129.

Cole, T.J., Bellizzi, M.C., Flegal, K.M., and Dietz, W.H. 2000. Establishing a standard definition for child overweight and obesity worldwide: International survey. BMJ, 320(7244): 1240-1243. doi:10.1136/bmj.320.7244.1240. PMID:10797032.

Daly, L.E., Kirke, P.N., Molloy, A., Weir, D.G., and Scott, J.M. 1995. Folate levels and neural tube defects. Implications for prevention. JAMA, 274(21): 1698-1702. doi:10.1001/jama.1995. 03530210052030. PMID:7474275.

De Wals, P., Tairou, F., Van Allen, M.I., Lowry, R.B., Evans, J.A., Van den Hof, M.C., et al. 2008. Spina bifida before and after folic acid fortification in Canada. Birth Defects Res. A Clin. Mol. Teratol. 82(9): 622-626. doi:10.1002/bdra.20485. PMID: 18655127.

Dietrich, M., Brown, C.J., and Block, G. 2005. The effect of folate fortification of cereal-grain products on blood folate status, dietary folate intake, and dietary folate sources among adult nonsupplement users in the United States. J. Am. Coll. Nutr. 24(4): 266-274. PMID:16093404.

Fazili, Z., Pfeiffer, C.M., Zhang, M., Jain, R.B., and Koontz, D. 2008. Influence of 5,10-methylenetetrahydrofolate reductase polymorphism on whole-blood folate concentrations measured by LC-M.S./ M.S., microbiologic assay, and bio-rad radioassay. Clin. Chem. 54(1): 197-201. doi:10.1373/clinchem.2007.096545. PMID: 18160726.

Health Canada. 2003. Canadian guidelines for body weight classification in adults. Cat no.: H49-179. Ottawa, Ont., Canada.

Health Canada. 2010a. Prenatal nutrition. Available from http://www. hc-sc.gc.ca/fn-an/nutrition/prenatal/index-eng.php. [Accessed 30 August 2011.]

Health Canada. 2010b. High dose folic acid supplementation questions and answers for health professionals. Available from http://www.hc-sc.gc.ca/fn-an/nutrition/prenatal/fol-qa-qr-eng. php\#a2. [Accessed 30 August 2011.]

Health Canada. 2011a. Drug Product Database. Ottawa, Ont., Canada. Available from http://www.hc-sc.gc.ca/dhp-mps/prodpharma/databasdon/index-eng.php. [Accessed 15 Aug 2011.]

Health Canada. 2011b. Licensed Natural Health Products Database. Ottawa, Ont., Canada. Available from http://www.hc-sc.gc.ca/ dhp-mps/prodnatur/applications/licen-prod/lnhpd-bdpsnh-eng.php. [Accessed 15 August 2011.]

Hirsch, S., Sanchez, H., Albala, C., Maza, M.P., Barrera, G., Leiva, L., and Bunout, D. 2009. Colon cancer in Chile before and after the start of the flour fortification program with folic acid. Eur. J. Gastroenterol. Hepatol. 21(4): 436-439. doi:10.1097/MEG. 0b013e328306ccdb. PMID:19190501.

Institute of Medicine. 1998. DRI dietary reference intakes for thiamin, riboflavin, niacin, vitamin $\mathrm{B}_{6}$, folate, vitamin $\mathrm{B}_{12}$, pantothenic acid, biotin, and choline. National Academy Press, Washington, D.C., USA.

Ly, A., Lee, H., Chen, J., Sie, K.K., Renlund, R., Medline, A., et al. 2011. Effect of maternal and postweaning folic acid supplementation on mammary tumor risk in the offspring. Cancer Res. 71(3): 988-997. doi:10.1158/0008-5472.CAN-10-2379. PMID: 21135116.

Mason, J.B., Dickstein, A., Jacques, P.F., Haggarty, P., Selhub, J., Dallal, G., and Rosenberg, I.H. 2007. A temporal association between folic acid fortification and an increase in colorectal cancer rates may be illuminating important biological principles: A hypothesis. Cancer Epidemiol. Biomarkers Prev. 16(7): 13251329. doi:10.1158/1055-9965.EPI-07-0329. PMID:17626997.

McNulty, B., Pentieva, K., Marshall, B., Ward, M., Molloy, A.M., Scott, J.M., and McNulty, H. 2011. Women's compliance with current folic acid recommendations and achievement of optimal vitamin status for preventing neural tube defects. Hum. Reprod. 26(6): 1530-1536. doi:10.1093/humrep/der078. PMID:21441543.

Nguyen, P., Tam, C., O'Connor, D.L., Kapur, B., and Koren, G. 2009. Steady state folate concentrations achieved with 5 compared with $1.1 \mathrm{mg}$ folic acid supplementation among women of childbearing age. Am. J. Clin. Nutr. 89(3): 844-852. doi:10. 3945/ajen.2008.26878. PMID:19158211.

Pfeiffer, C.M., Fazili, Z., and Zhang, M. 2010. Folate analytical methodology. In LB Bailey, editor. Folate in health in disease. 2nd ed. CRC Press, Taylor \& Francis Group. Boca Raton, Fla., USA.

Refsum, H. 2001. Folate, vitamin B12 and homocysteine in relation to birth defects and pregnancy outcome. Br. J. Nutr. 85(Suppl. 2): S109-S113. doi:10.1079/BJN2000302. PMID:11509098.

Rust, K.F., and Rao, J. 1996. Variance estimation for complex surveys using replication techniques. Stat. Methods Med. Res. 5(3): 283310. doi:10.1177/096228029600500305. PMID:8931197.

Shakur, Y.A., Garriguet, D., Corey, P., and O'Connor, D.L. 2010. Folic acid fortification above mandated levels results in a low prevalence of folate inadequacy among Canadians. Am. J. Clin. Nutr. 92(4): 818-825. doi:10.3945/ajen.2010.29696. PMID: 20739423.

Sherwood, K.L., Houghton, L.A., Tarasuk, V., and O'Connor, D.L. 2006. One-third of pregnant and lactating women may not be meeting their folate requirements from diet alone based on mandated levels of folic acid fortification. J. Nutr. 136(11): 2820 2826. PMID:17056807.

Shuaibi, A.M., House, J.D., and Sevenhuysen, G.P. 2008. Folate status of young Canadian women after folic acid fortification of grain products. J. Am. Diet. Assoc. 108(12): 2090-2094. doi:10. 1016/j.jada.2008.09.007. PMID:19027414.

Siemans Canada. 2006. Immulite 2000 vitamin $B_{12}$ package insert \#P1L2KVB-22. 2006. Siemans Canada Ltd. Mississauga, Ont., Canada.

Siemans Canada. 2009. Immulite 2000 folic acid insert. Siemans Canada Ltd., Mississauga, Ont., Canada.

Stabler, S., Clinical folate deficiency. 2010. In Folate in health and disease. 2nd ed. Edited by L.B. Bailey. CRC Press, Taylor \& Francis Group. Boca Raton, Fla., USA. pp. 409-428.

Statistics Canada. 2008. Income trends in Canada: 1980-2003. Ottawa, Ont., Canada. Cat no. 13F0022XIE. Available from http:// www.statcan.gc.ca/pub/13f0022x/00003/notedef/5801170-eng. htm\#famsize. [Accessed 29 March 2011.]

Statistics Canada. 2011a. Questionnaire $(s)$ and reporting guide $(s)-$ Canadian Health Measures Survey (CHMS). Ottawa, Ont., Canada. Available from http://www.statcan.gc.ca/cgi-bin/imdb/ p2SV.pl?Function=getInstrumentLink\&SurvItem_Id=9353\&Query_Id $=10263 \&$ Query $=$ instance $\&$ lang $=$ en $\& \mathrm{db}=$ imd$\mathrm{b} \& \mathrm{adm}=8 \& \mathrm{dis}=2$. [Accessed 4 April 2011.]

Statistics Canada. 2011b. Canadian Health Measures Survey (CHMS) Cycle 1 Wave 1 Derived Variable (DV) Specifications. Ottawa, ON. Available from http://www.statcan.gc.ca/imdb-bmdi/document/ 5071_D3_T9_V2-eng.pdf. [Accessed 18 April 2011.]

Stockley, L., and Lund, V. 2008. Use of folic acid supplements, particularly by low-income and young women: A series of systematic reviews to inform public health policy in the UK. Public Health Nutr. 11(8): 807-821. doi:10.1017/ S1368980008002346. PMID:18457601. 
Tam, C., McKenna, K., Goh, Y.I., Klieger-Grossman, C., O’Connor, D.L., Einarson, A., and Koren, G. 2009. Periconceptional folic acid supplementation: A new indication for therapeutic drug monitoring. Ther. Drug Monit. 31(3): 319-326. doi:10.1097/FTD. Ob013e31819f3340. PMID:19349928.

Tinker, S.C., Cogswell, M.E., Devine, O., and Berry, R.J. 2010. Folic acid intake among U.S. women aged 15-44 years, National Health and Nutrition Examination Survey, 2003-2006. Am. J. Prev. Med. 38(5): 534-542. doi:10.1016/j.amepre.2010.01.025. PMID: 20347553.
Vatanparast, H., Adolphe, J.L., and Whiting, S.J. 2010. Socioeconomic status and vitamin/ mineral supplement use in Canada. Health Rep. 21(4): 19-25. PMID:21269008.

Yajnik, C.S., Deshpande, S.S., Jackson, A.A., Refsum, H., Rao, S., Fisher, D.J., et al. 2008. Vitamin $\mathrm{B}_{12}$ and folate concentrations during pregnancy and insulin resistance in the offspring: The Pune maternal nutrition study. Diabetologia, 51(1): 29-38. doi:10.1007/ s00125-007-0793-y. PMID:17851649. 